\title{
ESTUDOS CULTURAIS COMO PROPOSTA DE ENSINO DE SEMÂNTICA: \\ RESSIGNIFICANDO A PRÁTICA DOCENTE
}

\section{CULTURAL STUDIES AS A PROPOSAL FOR TEACHING SEMANTICS: \\ RE-MEANING TEACHING PRACTICE}

\author{
Rodrigo Nunes da Silva ${ }^{1}$ \\ Linduarte Pereira Rodrigues ${ }^{2}$ \\ Universidade Estadual da Paraíba (UEPB)
}

\section{RESUMO}

O trabalho apresenta uma reflexão sobre os estudos culturais nas aulas de Língua Materna tendo como base a Semântica de Contextos e Cenários (SCC). Como pesquisa bibliográfica de natureza qualitativa, traz uma proposta de abordagem didático-pedagógica, levando em consideração o contexto cultural como perspectiva de ensino. Uma vez que os fenômenos culturais e a língua são elementos indissociáveis na constituição de sentidos de palavras e expressões de dada comunidade, o estudo objetiva sugerir possibilidades de ensino com vistas a desenvolver a proficiência leitora e o desenvolvimento de habilidades e conhecimentos essenciais à contemporaneidade. Para tanto, ancora-se em estudos realizados por Candau (2014), Ferrarezi Jr. (2008), Rodrigues (2009) e nos documentos oficiais (BRASIL, 1998; 2002; 2013), entre outras bases teóricas. A pesquisa aprofunda e atualiza conceitos semânticos numa abordagem cultural e contemporânea dos estudos linguísticos, valorizando práticas educativas regionais que a educação básica poderá utilizar como forma de letramento escolar.

PALAVRAS-CHAVE: Formação docente; Ensino de Língua Materna; Semântica cultural.

\begin{abstract}
This paper presents a reflection on cultural studies in Mother Language classes based on the Context and Scenario Semantics (SCC). As a qualitative bibliographical research, it brings a proposal of didactic-pedagogical approach, taking into consideration the cultural context as a teaching perspective. Since cultural phenomena and language are inseparable elements in the constitution of meanings of words and expressions of a given community, the study aims to suggest teaching possibilities in order to develop reading proficiency and the development of skills and knowledge essential to contemporary times. To this end, it is anchored in studies by Candau (2014), Ferrarezi Jr. (2008), Rodrigues (2009) and the official documents (BRASIL, 1998; 2002; 2013), among other theoretical bases, the research deepens and updates semantic concepts in a cultural and contemporary approach of the students. language studies, valuing regional educational practices that basic education can use as a form of school literacy.
\end{abstract}

KEYWORDS: Teacher training; Mother Language Teaching; Cultural semantics.

\footnotetext{
${ }^{1}$ Mestre em Linguagens, Culturas e Formação docente pela Universidade Estadual da Paraíba (UEPB). Email: rodryggonunes22@gmail.com

${ }^{2}$ Doutor em Linguística. Professor do Departamento de Letras e Artes e do Programa de Pós-Graduação em Formação de Professores da Universidade Estadual da Paraíba (UEPB). E-mail: linduartepr@gmail.com
} 


\section{PARA COMEÇO DE CONVERSA}

Estudos recorrentes na área da linguística deixam claro que é preciso repensar o modelo tradicional de ensino e transformar o ambiente escolar a partir da construção de um Currículo com viés cultural, uma vez que este leva em consideração a formação integral do aluno, rejeitando o modelo simplista, com foco em conteúdos elencados como única forma de ensinar e aprender. Faz-se necessário ampliar e potencializar ações no meio escolar tendo em vista a promoção de um ensino que leve em consideração o entrecruzamento de culturas e a construção de um Currículo multicultural que direcione para o ensino e aprendizagem de aulas de Língua Materna, com foco numa perspectiva de ensino que evidencie aspectos culturais.

Atualmente, na chamada era da cultura digital, exige-se um redimensionamento para o ensino, tendo em vista as novas abordagens e contextos comunicativos no processo de formação do alunado. Educadores, tendo consciência que precisam trazer esta discussão para o ambiente da escola, estão constantemente à procura de "ressignificar" a forma de agir, visando como elemento central o próprio aluno, sujeito inserido na sociedade, detentor de não apenas uma forma de cultura, não apenas um modelo autônomo de letramento, mas de uma gama cultural, de multiletramentos ideológicos.

Desta feita, elencamos possibilidades para um trabalho interdisciplinar nas aulas de Língua Materna, que envolva conceitos de aspectos culturais e fenômenos linguísticos no contexto escolar. Nosso trabalho justifica-se pela necessidade de estudos sobre a linguagem que envolva de fato os fenômenos culturais no ambiente escolar. Diante disso, quando o assunto é a educação na era da cultura digital, destacamos as seguintes questões problema: Como a semântica cultural pode contribuir nas aulas de Língua Materna visando despertar a leitura crítica dos alunos da educação básica? Como trabalhar esses aspectos em sala de aula? E por onde começar?

Para responder tais questionamentos, buscamos apresentar possibilidades de atividades a partir da Semântica de Contextos e Cenários (FERRAREZI JR., 2008, p. 23), a qual "toma como base a ideia de que uma língua natural é um sistema de representação do mundo e de seus eventos". Além desse apoio teórico, através de uma pesquisa bibliográfica, buscamos base teórica nas leituras efetuadas em Candau (2014), sobre a condição dos professores frente às novas demandas da educação; em Rodrigues (2009), sobre representações de autor, leitor e leitura; e nos documentos oficiais (BRASIL, 1998; 2002; 2013), os quais apontam para a valorização da pluralidade do patrimônio sociocultural, buscando desenvolver no aluno seu potencial crítico, a percepção das múltiplas possibilidades de expressão linguística, além da capacitação como leitor efetivo dos mais diversos textos representativos de nossa cultura. A finalidade é desenvolver nos alunos a proficiência leitora e o aprimoramento dos sentidos de palavras e expressões que fazem parte do cotidiano do alunado da região Nordeste.

Observamos que é importante que o professor leve seu aluno a se conscientizar de sua própria cultura linguística, a partir de uma visão autocrítica e reflexiva da sociedade e dos fenômenos linguístico-culturais e/ou do grupo em que ele vive, destacando a importância do autoconhecimento e da constituição de sua própria identidade e de aspectos linguísticos locais. Isso pode ser feito a partir da circulação de gêneros textuais diversos no ambiente escolar como, por exemplo, folhetos de cordel, que permitem trazer para sala de aula uma gama de temas, fazendo com que o alunado entre em contato com formas variadas de práticas e eventos de letramento. Dessa forma, a instituição escolar deve funcionar como espaço que propicie a discussão sobre essas novas relações culturais, entendendo a dimensão histórica, social e política do sujeito. A educação precisa contribuir para a reflexão equilibrada, permeada pela inclusão dos vários fenômenos linguísticos e o respeito às diferenças culturais. 


\section{Cultura, ensino de Língua Materna e formação docente}

Podemos dizer que assim como a sociedade está em constante mudança, consequentemente as relações culturais estão em contínuo processo de reconstituição. Apesar de todas as culturas possuírem uma origem, elas também possuem uma história não estática, mas dinâmica. Levar estas questões para sala de aula é pensar nos educandos como sujeitos interativos, que possuem uma identidade aberta, flexível e em constante construção. Dentro deste contexto de pluralidade, o aluno torna-se um sujeito híbrido, otimizado, capaz de dialogar e trocar experiências com o meio em que vive e a diversidade cultural a que tem acesso.

Silva (2010, p. 8) explica que

Vivemos num tempo de afirmação da identidade hegemônica do sujeito otimizado [...]. É num tempo como esse que nós, educadores e educadoras (pós)críticos/as, nos vemos moralmente obrigados, mais do que nunca, a fazer perguntas cruciais, vitais, sobre nosso ofício e nosso papel, sobre nosso trabalho e nossa responsabilidade.

É de Candau (2014, p. 45) o pensamento de que é pelo viés e mediação da dimensão dialógica da educação que o professor deve realizar seu trabalho, "pelo fato de considerar que os seres humanos se conhecem e transformam a realidade como sujeitos". Diante disso, vemos que é de significativa importância articular saberes, identidades e representações culturais de âmbito local, e também global, em propostas educacionais.

[...] o papel da educação é fundamental, pois incide no imaginário coletivo, nas mentalidades, nas representações das identidades sociais e culturais presentes na nossa sociedade e nos colocam diante da necessidade de aprofundar na compreensão das relações entre educação e culturas (CANDAU, 2014, p. 36).

Para repensar o Currículo, com o objetivo de trabalhar conceitos da Semântica Cultural em sala de aula, se faz necessário rever a centralidade do conhecimento nas definições de Currículo em alguns documentos oficiais, como as apresentadas nas Diretrizes Curriculares Nacionais (BRASIL, 2013, art. 13), em que o currículo se faz pelas

[...] experiências escolares que se desdobram em torno do conhecimento, permeadas pelas relações sociais, articulando vivências e saberes dos estudantes com os conhecimentos historicamente acumulados e contribuindo para construir as identidades dos educandos.

Segundo Moreira (2007, p.288), "há que se considerar o aluno em suas diferentes dimensões". Compreendemos que a escola, para educar, precisa colocar o ensino sob suspeita, o que implica redimensionar a própria concepção de Currículo.

O professor de Língua Materna, como agente transformador, é responsável por estabelecer a mediação entre os conhecimentos culturais locais e o aluno. Para isso, se faz necessário uma nova leitura dos conteúdos curriculares, fato que causa insegurança e desestabiliza o trabalho docente. Tem-se de implantar um trabalho no qual se desenvolva "Currículos coerentes com a interculturalidade" (CANDAU, 2014, p.14). Essa medida levará o professor a construir em sala de aula um ambiente de interação através do conhecimento do "outro", e de autoconhecer-se, ou seja, o conhecimento de "nós", eliminando os possíveis conflitos e desafios levantados, compartilhando e dialogando experiências múltiplas, para assim desenvolver o respeito pelo diferente, indo contra toda forma de preconceito e discriminação.

Dessa forma, o professor de Língua Materna pode promover atividades que envolvam a multiplicidade de usos efetivos da língua(gem), da leitura e escrita nos mais diversos contextos 
sociais, levando em consideração a interação como lugar constitutivo de formação de sujeitos, pois assim estará desenvolvendo práticas condizentes com as que apontam os PCN+ (BRASIL, 2002, p.55) como objetivos gerais para o ensino de língua materna:

O ensino de língua portuguesa, hoje, busca desenvolver no aluno seu potencial crítico, sua percepção das múltiplas possibilidades de expressão linguísticas, sua capacitação como leitor efetivo dos mais diversos textos representativos de nossa cultura. Para além da memorização mecânica de regras gramaticais ou das características de determinado movimento literário, o aluno deve ter meios para ampliar e articular conhecimentos e competências que possam ser mobilizados nas inúmeras situações de uso da língua com que se depara, na família, entre amigos, na escola, no mundo do trabalho.

Propostas que permitam ao aluno trabalhar com os usos efetivos da língua, relacionando o trabalho com a linguagem, a leitura ou a produção de textos em sala de aula, possibilitam a formação de habilidades efetivas, ao levar os indivíduos envolvidos a assumir criticamente e criativamente a sua função de sujeito do discurso nas atividades propostas. O docente deve refletir não sobre como a língua afeta os alunos em sala de aula, mas como os alunos afetam a língua, levando em consideração que os sujeitos não são "tábuas rasas", mas estão inseridos dentro de um contexto social, histórico e cultural.

Ressaltamos que um dos objetivos para o ensino de língua portuguesa, apontado pelos PCN (BRASIL, 1998, p.7), é justamente:

Conhecer e valorizar a pluralidade do patrimônio sociocultural brasileiro, bem como aspectos socioculturais de outros povos e nações, posicionando-se contra qualquer discriminação baseada em diferenças culturais, de classe social, de crenças, de sexo, de etnia ou outras características individuais e sociais.

No entanto, apesar das propostas dos PCN apontarem para um ensino da língua em contextos de comunicação real, formando cidadãos críticos e reflexivos, atuantes e transformadores de realidades, ainda há muitas salas de aulas cujo ensino é focado, por exemplo, em exercícios de fixação de regras gramaticais. Além disso, não se leva em consideração a macroestrutura do texto literário e a pluralidade de significações da língua. Essas lacunas no ensino de língua materna são contrárias à proposta de integração entre língua, sujeitos e situações de comunicação apresentada pelo professor Geraldi, no início da década de 90. Para ele,

Não se domina uma língua pela incorporação de um conjunto de itens lexicais (o vocabulário); pela aprendizagem de um conjunto de regras de estruturação de enunciados (gramática); pela apreensão de um conjunto de máximas ou princípios de como participar de uma conversação ou de como construir um texto bem montado sobre determinado tema (GERALDI, 1991, p. 17).

O contexto escolar e a cultura estão imbricados, não podendo ser concebidos independentes, mas numa relação de entrelaçamento. Dessa forma, nossa maneira de viver e interagir com os outros mostra a que visão de mundo estamos atrelados. Assim, entendemos, de acordo com Sacristán (2002, p.99), que "a cultura é a base de um potente vínculo social que nos aproxima das pessoas com quem compartilhamos as representações do mundo, os traços culturais em geral e os modos de comunicação, formando um genérico nós cultural”. Logo, existe uma interrelação do contexto cultural com dimensões múltiplas de ordem política, ideológica, social, econômica, educacional, entre outras, levando em consideração o valor das diversas contribuições identitárias culturais na sociedade. Candau (2014) deixa claro que as escolas, como instituições educacionais, também são instituições culturais. Logo, não se podem ignorar os 
diversos grupos sociais, as formas de ser e agir, de se expressar, para que as manifestações cultuais consideradas não tradicionais possam ser reconhecidas e valorizadas no ambiente escolar.

Com a adoção dessas ações, esperamos que as aulas de língua materna se tornem mais produtivas, pelo fato de educar para a convivência, para construção de saberes locais e globais, transpassados de realidade para os educandos. Com isso, o estudo de língua(gens) ganha sentido, pois o aluno adquire e desenvolve habilidades de diferenciar, selecionar, compartilhar e interagir com o outro, utilizando os recursos da linguagem para produzir os efeitos de sentido desejados, pautados, acima de tudo, no respeito às diferenças sociais, históricas, linguísticas e culturais.

\section{Ser leitor na era da cultura digital}

A era digital desafia os professores a se reinventarem. Um novo perfil de leitor entra em cena, mais rápido, sem tempo para parar, aprofundar... O ato de ler se torna dinâmico, cheio de idas e vindas. Além disso, é consenso pesquisas na área da educação, com foco no ensino e aprendizagem da leitura e interpretação textual, apontarem para o fato de existir um distanciamento entre a prática docente e as orientações sugeridas pelos documentos oficiais.

As novas tecnologias transformaram as situações de comunicação e a maneira de buscar informações. É comum ouvir de professores que, com o advento das novas tecnologias, o alunado se distanciou ainda mais dos livros impressos, fazendo com que novas abordagens fossem repensadas para se atingir as habilidades e competências propostas para cada fase da educação básica. Como visto, temos um novo perfil do sujeito leitor, caracterizado pela ação contínua da rapidez, sem muito aprofundamento.

Não podemos pensar em práticas de letramento eficazes no ambiente escolar e na perspectiva cultural sem levar em consideração o contexto social em que se está inserido. As novas tecnologias introduziram um novo conceito de comunidade, em que o importante não é mais a proximidade das pessoas, mas os interesses comuns. A internet cria conexões entre pessoas, ideias, informações. Tudo gerou mudanças drásticas nas atividades de sala de aula; o advento desses recursos trouxe enormes responsabilidades para os educadores. Com isso, observam-se grandes desafios postos a educação como um todo, especificamente ao professor de Língua Materna ao promover o ensino da leitura.

Diante das mudanças provocadas por este fenômeno tecnológico, começamos a questionar nossa postura como profissionais da educação frente aos nossos compromissos perante a escola e a sociedade, buscando capacitações que nos auxiliem nesse momento. É preciso que haja um ambiente na escola em que se possa discutir a elaboração e apresentação de políticas públicas voltadas para inclusão digital e para as novas demandas do ato de ler, tendo em vista a inserção dos alunos, de maneira crítica e reflexiva, frente a este novo momento da história da humanidade.

É consenso, a instituição escolar passa por um processo de transformação significativo, característico de um mundo cada vez mais globalizado. Os avanços tecnológicos surpreendem pela rapidez e inovação. As crianças já "nascem conectadas", inseridas neste universo digital: celulares, tablets, computadores e outras ferramentas influenciam na formação social e consequentemente na formação leitora. Cabe a escola a função de fazer a integração do contexto tecnológico, comum no cotidiano dos educandos, ao âmbito educacional.

Com as nuances do texto cibernético, Sodré (2012) ressalta que este "novo leitor, advindo pelas novas tecnologias digitais, vai além da demanda de novas formas do ato de ler". Hoje, o ensino à distância é fato e tende a crescer cada vez mais. O texto eletrônico possui características significativas, que vai além do suporte e da palavra; é um emaranhado de palavras, imagens (em movimento ou estáticas), vídeos, sons, etc. Tudo isso fomenta uma diversidade de possibilidades para o ensino de leitura on-line, ampliando o escopo para o surgimento de novas ferramentas digitais. Diante disso, o professor de Língua Materna pode promover um ensino participativo e 
integrador, fazendo uso dessas novas abordagens de comunicação em múltiplas redes, transpassando o plano cultural de ensino.

No entanto, o que se vê em muitas escolas, ainda, é a imensa dificuldade dos docentes em fazer do ambiente de sala de aula um local de ensino e aprendizagem transpassado por realidade, e as aulas de leitura não fogem a esse dilema. Como promover a leitura em sala de aula levando em consideração essas demandas da contemporaneidade? Como formar leitores competentes, capazes de interagir e construir no contexto social em que estão inseridos?

De acordo com as Diretrizes Curriculares da Educação Básica, (2008, p. 48),

Refletir sobre o ensino da Língua e da Literatura implica pensar também as contradições, as diferenças e os paradoxos do quadro complexo da contemporaneidade. Mesmo vivendo em época denominada 'era da informação', a qual possibilita acesso rápido à leitura de uma gama imensurável de informações, convivemos com o índice crescente de analfabetismo funcional, e os resultados das avaliações educacionais revelam baixo desempenho do aluno em relação à compreensão dos textos que lê.

Como vimos, pode-se começar pela forma como o próprio texto, enquanto discurso, é tomado em sala de aula. São inúmeras pesquisas que apontam para o fato de que os alunos não encontram sentidos nas atividades propostas pela escola. Na maioria das vezes o texto é tomado como mero pretexto para o ensino de gramática. Não queremos aqui desmerecer o ensino gramatical. Acreditamos que a aprendizagem dos conteúdos gramaticais, na medida em que são trabalhados, levando em consideração o texto como um todo, desempenha papel significativo no desenvolvimento linguístico dos alunos, inclusive na leitura e produção textual. Porém, o que ocorre na maioria das vezes é que se deixa de considerar a leitura e a compreensão efetiva do texto como parte fundamental aos próprios estudos gramaticais.

Também é recorrente ouvir docentes relatarem que os alunos não se interessam pelas atividades de leitura sugeridas, talvez pelo fato de "não gostam de ler". Alguns jugam ser uma terrível tragédia o surgimento de tecnológicas digitais, como as redes sociais que se, por um lado aperfeiçoa o ato comunicativo, por outro, distancia a comunicação face a face, à interação humana, "viciando os alunos", que alegam não terem mais tempo para estudar. Acreditamos que a utilização de aplicativos/suportes digitais poderiam sim servir como instrumento constante de ensino, uma vez que fazem parte do cotidiano do alunado e promovem, através da mediação e interação do docente, aprendizagens reais.

A Associação de Leitura do Brasil (ALB) apresenta dados que revelam que gêneros ou suportes textuais como os gêneros digitais, rótulos de produtos, livros religiosos, jornais populares, livros de autoajuda e folhetos de feira, não são tomados como leitura nos ambientes escolares e extraescolares. Isso se evidencia pelo fato de que se foi construindo ao longo da história uma ideia enigmática do ato de ler e de livro.

Rodrigues (2009, p.1) argumenta ser preconceituoso e ultrapassado, para os estudos das Ciências Humanas, valorizar uma produção "clássica" em detrimento a uma considerada "vulgar". O autor diz que há um verdadeiro antagonismo entre uma cultura dita erudita e, por outro lado, uma considerada vulgar. O que se precisa de fato é entender os fenômenos sobre texto e linguagem e sobre representações correntes de autor, leitor e leitura. Por isso, sugere uma reflexão acerca da "recorrência do fenômeno da diversidade cultural que atende a multiplicidade do pensar humano, suas formas de linguagem, bem como as representações simbólicas cristalizadas em formações discursivas" (RODRIGUES, 2009, p.1).

Ressaltamos que as práticas e intervenções pedagógicas de sala de aula em favor da leitura são, muitas vezes, "enquadradas" numa concepção de que leitura que favorece poucos leitores. Há o esquecimento de que a leitura não é uma prática neutra e que é transpassada por questões culturais, políticas, histórias e sociais. Por isso, é preciso considerar as diferentes possibilidades de leitura. Rodrigues (2009, p.11) afirmar que não existe leitura pior, ou melhor. Ele entende que a 
"diferença não precisa ser sinônimo de desigualdade", além de perceber "que os discursos convencionais sobre a leitura estigmatizam grupos sociais e práticas culturais legitimadas". Ele argumenta que nas escolas buscam-se "apagar as provas que indicam que a leitura não é escassa no Brasil e negam os objetos, as práticas, as próprias pessoas que leem. E, assim, o povo brasileiro passa a figurar na história como os desprovidos do poder da leitura" (RODRIGUES, 2009, p.11).

Um trabalho significativo de leitura numa perspectiva cultural de ensino requer levar em consideração o processo de interação, de trocas de experiências entre autor, leitor e o mundo no qual se está inserido. Precisamos pensar sobre práticas escolares que emergem de um contexto social, histórico e cultural próprios dos leitores. É consenso que para se formar leitores proficientes não basta que o indivíduo saiba ler, é preciso que ele faça uso dessa habilidade. Ao refletir sobre a leitura numa perspectiva de análise e reflexão da língua, concordamos com Geraldi (2014), para quem a análise e reflexão linguística acontecem ao mesmo tempo em que se lê. Isso se dá na medida em que a leitura proporciona a construção e uma compreensão de sentidos além da materialidade do texto e de sua produção, pois os sujeitos leitores ativam o conhecimento de mundo para compreender o texto.

A seguir, destacamos os aspectos semânticos e culturais como forma de ensino de língua(gem), considerando o fato da relevância do conteúdo expressivo, remetendo para as formas de percepção do mundo, a referenciação de objeto e os sentidos diversos.

\section{Semântica de Contextos e Cenários (SCC) na aula de Língua Materna}

Nosso trabalho se enquadra numa corrente de pesquisa que permite atualizar os conceitos das diversas semânticas numa abordagem cultural e contemporânea dos estudos da linguagem. A Semântica de Contextos e Cenários (SCC) "toma como base a ideia de que uma língua natural é um sistema de representação do mundo e de seus eventos" (FERRAREZI. JR, 2008, p.23). Dessa forma, a cultura é a ponte entre o indivíduo e o mundo. Em sala de aula, os alunos deviam enxergar o mundo a partir da perspectiva cultural. Língua e cultura estão totalmente imbricadas na construção dos sentidos, para que a partir deles se faça a devida associação com outros aspectos dessa representação.

Esta é uma possibilidade de valorização dos estudos linguísticos, na medida em que se torna um campo de estudos que perpassa por contextos e abordagens multidisciplinares. Segundo Ferrarezi Jr. (2008, p.23),

Sempre que estudamos uma língua desse ponto de vista, o fazemos em relação à parte viva da língua (a língua em uso), o que caracteriza o estudo como pragmático, e o fazemos com base na cultura que aquela língua representa, o que caracteriza o estudo como cultural (histórico, antropológico, sociológico, tecnológico, etc.). Toda semântica assim praticada será, portanto, uma ciência interfacial, ou seja, atuará nas diferentes interfaces envolvidas pelo objeto língua. Será sempre uma 'Semântica Pragmático-cultural'.

Segundo a concepção da SCC, a semântica é a ciência que estuda as manifestações linguísticas do significado. Ressaltamos a diferença entre significado e sentido: "O significado é visto como aquilo que é cognitivamente ativado pela linguagem no nível neurológico", cógnito. Quanto ao sentido, Ferrarezi Jr. (2008, p.22) comenta que

[...] é composto por um conjunto de traços de significados culturalmente construídos, atribuídos e relevantes para uma comunidade, que esta mesma comunidade utiliza para fazer representar, por meio de sinais, os elementos ou eventos de um mundo qualquer. 
Tanto o sentido quanto o significado são fatores relevantes para a semântica e a pragmática, ciências que perscrutam a significação das coisas, o ato ou efeito de significar. Assim, a língua materna é a primeira forma de representação de um falante, que dá sentido a seu mundo a partir de uma referência real, simbólica ou imaginária de mundo. Essa língua natural "usa sinais cujos sentidos são especializados em um contexto, sendo que este só tem sentido especializado em um cenário". Daí surge o termo Semântica de contextos e cenários (SCC), associando as manifestações linguísticas aos sentidos, o que revela uma cultura, inter-relacionada "com um pensamento que gera e com um sistema linguístico que a representa". As formas de representação só são possíveis no cenário cultural. "Representar é, portanto, ter a possibilidade de usar no lugar de, pôr no lugar de" (FERRAREZI JR., 2008, p.24).

Observa-se que o conceito de representação é pensado como uma forma em que a língua expressa é posta pelos interlocutores "no lugar de", para que haja interação, comunicação, assumindo diversas funções, seja elas referenciar, criar possibilidades, percorrer contextos culturais, etc. Dessa forma, "a língua apresenta uma dimensão representativa, "instrumental”, mas também uma dimensão de espaço cultural, em que os sentidos são compartilhados em complexas interações culturalmente dirigidas, entre os falantes dessa língua" (FERRAREZI JR., 2008, p.25).

Percebemos que ao enunciar uma palavra, seja em que situação for, o sentido só será possível a partir do contexto em que tal palavra é proferida, contexto esse conhecido pelos interlocutores sendo local de produção de sentidos, o cenário. Ferrarezi Jr. (2008, p.26) chama de especialização do sentido,

A definição exata do sentido associado a um sinal-palavra em uso. Ou seja: um sinal-palavra $\mathrm{X}$, em um contexto $\mathrm{Y}$ e um cenário $\mathrm{W}$, devidamente identificados e definidos, estará associado a um e apenas um sentido $\mathrm{S}$ e, portanto, servirá para representar uma e apenas uma visão de referência $\mathrm{V}$, e não outra, em um mundo $\mathrm{M}$.

A partir dessa visão, o autor apresenta os conceitos de cenários adequados e sentidos costumeiros de uma palavra, os quais variam de cultura para cultura e de indivíduo para indivíduo. Com isso, evidencia que os falantes estão sempre atentos a qualquer mudança na língua. Ressaltamos as ideias de Ferrarezi Jr. (2008, p.31) no que diz respeito ao fato de que "existem tantos sentido quanto forem necessários para a representação de um mundo conforme a visão de referência, ou seja, conforme a cultura relacionada àquela língua permite ver esse mundo".

Diante disso, é fundamental refletirmos sobre formas de ensino a partir da semântica cultural. Para sintetizarmos as diferenças de ensino a partir da SCC, concordamos com Ferrarezi Jr. (2008) ao apresentar um quadro comparativo entre as vantagens de se trabalhar a semântica cultural frente ao ensino tradicional de língua materna. Vejamos:

Quadro 1. Vantagens do ensino da SCC em sala de aula

\begin{tabular}{|l|l|}
\hline \multicolumn{1}{|c|}{ ENSINO TRADICIONAL } & \multicolumn{1}{c|}{ ENSINO ATRAVÉS DA SCC } \\
\hline $\begin{array}{l}\text { A língua materna é enfocada a partir de sua } \\
\text { estrutura gramatical e desvinculada de } \\
\text { valores culturais e de uso efetivo. }\end{array}$ & $\begin{array}{l}\text { A língua materna é enfocada a partir de sua relação com } \\
\text { a cultura e de seu uso efetivo, sendo que a estrutura } \\
\text { gramatical, quando analisada, é vista como uma } \\
\text { implicação das necessidades representativas próprias de } \\
\text { uma língua. }\end{array}$ \\
$\begin{array}{l}\text { O aluno não conhece sua língua na língua } \\
\text { da escola e tem dificuldade de relacionar a } \\
\text { língua da escola e sua cultura. }\end{array}$ & $\begin{array}{l}\text { O aluno reconhece na língua da escola sua língua e } \\
\text { aprende que há uma variante de prestígio que pode ser } \\
\text { aprendida e dominada para fins específicos. }\end{array}$ \\
\hline
\end{tabular}




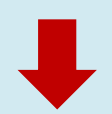

A língua ensinada na escola se torna uma "língua artificial", cujo uso se restringe aos objetivos da escola, e isso cria uma sensação de imposição escolar em relação à língua materna.

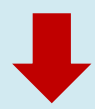

Todos os fatores acima resultam em profundo desgosto com a matéria. Surge a frase, infelizmente, tão comum: "Odeio as aulas de Português!"”.

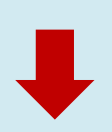

A língua ensinada na escola é a língua que o aluno fala efetivamente, além de serem ensinadas outras variantes de interesse. Isso cria uma sensação de valor pessoal e de que a aprendizagem proposta será verdadeiramente útil para a vida do aluno.

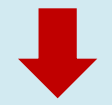

Todos os fatores acima tendem a resultar em gosto pela relação matéria. Espera-se que os alunos apreciem o processo de aprendizagem e aperfeiçoamento das suas habilidades linguísticas, e acabem demonstrando isso: "Gosto das aulas de brasileiro!".

Fonte: Ferrarezi Jr. (2008, p.33)

De acordo com a visão do autor, com a SCC os alunos podem se interessar mais pelas aulas de língua materna, uma vez que o processo de ensino e aprendizagem engloba as experiências reais da vida, reforçando o vínculo "escola-vida". Assim como a língua é dinâmica e está sempre a mudar, as situações de interação/comunicação também sempre mudam, mudando os sentidos que empregamos para determinada palavra num dado contexto.

\subsection{Metáforas funcionais}

$\mathrm{Na}$ língua portuguesa existem diversos recursos de linguagem que os escritores utilizam para construírem efeitos de comunicação desejados. Dentre elas, destaca-se a metáfora. Nos estudos de tradição retórica, a metáfora é vista apenas como uma figura de linguagem que os escritores utilizam para "ornamentar" seus textos. Entretanto, as metáforas são importantes recursos de registro da visão de mundo de um povo, dizem respeito a nossa formação cultural (FERRAREZI JR., 2012). Observando o aspecto representativo da língua, o professor pode enveredar pelo estudo das metáforas na construção de textos.

Ressaltamos que a metáfora não é somente uma questão linguística, mas uma construção conceitual que envolve o intelecto e as dimensões naturais da experiência, que envolve domínios do abstrato e do emocional, como experiências sensoriais de formas, sons, cores, etc. Comumente, a metáfora é apresentada como uma propriedade estruturante a partir de sua relação com o contexto cultural e seu modo organizacional. Ferrarezi Jr. (2012, p.69) tece considerações sobre as metáforas funcionais, aquelas advindas dos processos de nomeação que exercem uma função clara de registro cultural, ou seja,

Uma construção figurativa na qual a palavra metaforicamente construída apresenta uma clara função de depósito cultural, uma função de registro de algum tipo de conhecimento resultante das experiências vivenciais dessa mesma comunidade que atribuiu esse nome metafórico a um referente.

Para o autor, as metáforas funcionam como registros da visão de mundo dos falantes de determinada cultura, servindo como forma de expressão da organização cultural das experiências locais e, assim, com marca de identidade. Para Ferrarezi Jr. (2012, p.71), 
Metáfora é um tipo de construção linguística que permite a atribuição de um sentido construído dentro de um paradigma cultural definido a outra palavra (ou construção multivocabular ${ }^{3}$ ) que, em seu sentido costumeiro, isto é, no sentido usual dessa palavra ou expressão na comunidade de falantes, pertencia a outro paradigma cultural estabelecido.

Segundo ele, grande parte das metáforas que fazem parte de uma língua são palavras do cotidiano, atribuídas pelo modo se expressar dos falantes aos diversos referentes que representam. Assim, o fenômeno conhecido como "metáfora funcional" é evidenciado por Ferrarezi Jr. (2012) com "uma clara função de depósito cultural”, condicionada ao tempo e como registro dos valores culturais estabelecidos por um povo. Esses registros são advindos das experiências vividas pelo grupo que atribuiu um determinado nome ao referente, podendo levar a influências no modo de funcionamento da língua, seja uma perda de identidade cultural ou evolução da mesma, dependendo do referente em questão.

\title{
4 Abordagens de ensino derivadas da SCC: modos de fazer
}

Nas aulas de Língua Materna o professor pode investigar os conhecimentos prévios dos alunos sobre a experiência pessoal, social e cultural, desenvolvendo atividades exploratórias com vista a levar o aluno a valorizar sua cultural, não desprezando as outras. A linguagem desenvolvida na comunidade, os modos de falar, os costumes, entre outros aspectos podem ser destacados no trabalho com o sentido das palavras e suas representações, sabendo que é a partir da língua(gem) que os falantes registram seus saberes culturais.

Ao se pensar na região Nordeste, por exemplo, podem-se elaborar propostas de trabalho a partir de folhetos de cordel, uma vez que esta forma de expressão linguístico-literária traz em sua macroestrutura elementos significativos de ensino local: palavras e expressões, identificação cultural, representações simbólicas, entre outros elementos que enriquecem o ambiente de sala de aula. Em trabalhos anteriores (SILVA, 2014; RODRIGUES, 2011), argumentamos que nos folhetos de feira há variedade de temas, tradicionais ou contemporâneos, que refletem a vivência popular, desde problemas atuais até a conservação de narrativas inspiradas no imaginário do povo e proveniente da tradição oral.

A construção cultural dos nordestinos é imensa e muito diversificada, com diferenças regionais bem marcadas, e isso é representado nos folhetos de cordel. Segundo Ferrarezi Jr. (2008, p.33), "o ensino com base na semântica de contextos e cenários é um ensino da língua materna viva". Um exemplo é o conjunto de escritos do cearense Patativa do Assaré, um dos mais importantes representantes da cultura popular nordestina:

\author{
Nesta batalha danada \\ Correndo de lá prá cá \\ Tenho a pele bronzeada \\ Do sol do meu Ceará \\ (PATATIVA DO ASSARÉ, s/d)
}
Não nego meu sangue, não nego meu nome,
Olho para fome e pergunto: o que há?
Eu sou brasilêro fio do Nordeste,
Sou cabra da peste, sou do Ceará.
(PATATIVA DO ASSARÉ, 2008)

\footnotetext{
${ }^{3}$ Expressão advinda da hipótese maturacional de Radford (1993). Para ele existem diferentes fases para a aquisição da linguagem. Há uma maturação de uma para outra: $1^{\circ}$ Fase pré-linguística -0 a 12 meses; $2^{\circ}$ Fase de uma só palavra -12 a 18 meses; $3^{\circ}$ Fase multivocabular inicial ou lexical -18 a 24 meses; $4^{\circ}$ Fase multivocabular tardia ou funcional -24 a 30 meses.
} 
Essas palavras e expressões ecoam da tradição popular nordestina e possibilitam um trabalho significativo em sala de aula que compõe a educação básica brasileira. Vale salientar que os exemplos mencionados anteriormente são facilmente encontrados nos meios virtuais. Ressaltamos que a literatura de cordel é uma das principais manifestações da cultura popular, contrariando muitos pesquisadores que pensavam que, com o advento dos tempos modernos e a ampla difusão de meios de comunicação diversos, o cordel teria seu fim. Observamos que há uma evolução dessa literatura, tendo o encontro de novos mecanismos de midiatização, como por exemplo, a Internet (RODRIGUES, 2014).

Rodrigues (2014, p.161) explica que hoje não se pendura mais folhetos em barbantes, como sustenta a tradição reproduzida como fetiche em "dia do folclore" nas escolas ou eventos midiáticos de tradição junina. O cordel transita hoje em "ondas virtuais da Web, para assegurar o seu posto de pós, daquilo que estando no presente não abre mão do imaginário de sua gente para recontá-lo e manter acesa a chama de um povo que caminha entre tempos de modificação constante". Para Mello (2013, p. 175),

A inclusão do ciberespaço no espaço escolar substitui um ambiente passivo e possibilita ao aluno perceber as mudanças na concepção de leitor, que passa a ser um coautor do texto. A leitura, por sua vez, passa, simultaneamente, a escritura. O leitor, escolhendo o caminho da leitura e o conteúdo a ser lido, transforma-se numa espécie do editor do hipertexto em construção, enquanto o texto passa a ser móvel.

Nesta perspectiva, a leitura do cordel digital "Emigração e as consequências", de Patativa do Assaré, torna-se uma possibilidade de tematizar sobre o fenômeno da migração nordestina, a estagnação econômica, as constantes secas etc.

Neste estilo popular

Nos meus singelos versinhos,

O leitor vai encontrar

Em vez de rosas espinhos

$\mathrm{Na}$ minha penosa lida

Conheço do mar da vida

As temerosas tormentas

Eu sou o poeta da roça

Tenho mão calosa e grossa

Do cabo das ferramentas

Por força da natureza

Sou poeta nordestino

Porém só conto a pobreza

Do meu mundo pequenino

Eu não sei contar as glórias

Nem também conto as vitórias

Do herói com seu brasão

Nem o mar com suas águas

Só sei contar minhas mágoas

E as mágoas do meu irmão

$[\ldots]$

Meu bom Jesus Nazareno

Pela vossa majestade

Fazei que cada pequeno 


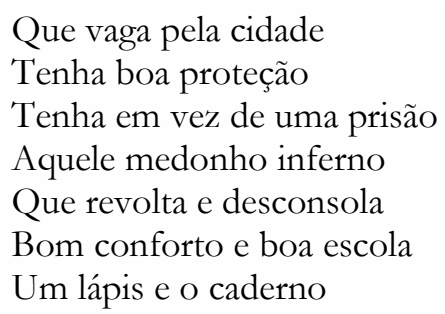

Ao longo da leitura do folheto, o professor pode destacar questões referentes ao tema, a partir de recursos semânticos, tais como: metáforas, sinônimos, além de aspectos ideológicos, como a religiosidade do povo nordestino, identidade, identificação e representação.

Muitas vezes, as pessoas não querem ou não conseguem expressar o que realmente sentem. Então falam por meio de metáforas, em que seu significado fica subentendido. Diante disso, o conceito de metáfora pode ser trabalhado, apresentando-a como fenômeno linguístico muito utilizado no dia a dia, sendo importantíssima na comunicação/interação humana. Seria relevante trazer também outros exemplos para dialogar com o texto. Dessa forma, pontuar a relação dos vocábulos "escola", "proteção", "consolo" X "inferno", "prisão" e "revolta", presentes no folheto, seria uma possibilidade plausível de evidenciar os sentidos antônimos e os efeitos de sentido criados pelo poeta popular no texto em questão.

Para ressaltar, trazemos uma situação de pesquisa, vivenciada anteriormente no contexto de sala de aula da educação básica (SILVA, 2017). A pesquisa traz uma proposta de trabalho com o cordel supracitado, a partir de uma perspectiva cultural de ensino, com foco na SCC. Trata-se de uma pesquisa-ação. Os alunos foram identificados por números, para preservar suas identidades. Ao considerar a primeira estrofe do poema, uma das alunas disse:

Aluna 4: - Se rosa pode ser metáfora de uma coisa boa, então eu posso falar "minha vida é uma rosa" (A aluna retoma um trecho do cordel já discutido em sala).

Professor pesquisador: - Muito bem. Isso mesmo, no caso você estará afirmando que sua vida é boa, certo?

Aluno 13: - E "minha vida é cheia de pedra" no lugar de espinhos?

Professor pesquisador: - Bom, depende do que você quer transmitir ou comunicar, certo. Veja bem, dizer que sua vida é cheia de pedras, essas pedras, metaforicamente quer dizer o quê?

Aluno 13: - Quer dizer que é cheia de.... (o aluno fica em silêncio)

Professor pesquisador: - Cheia de obstáculos, barreiras, correto?

Aluno 13: - É, é isso mesmo.

A fala da aluna 25 evidencia o emprego do termo utilizado no folheto de cordel quando o poeta diz: "Nesta batalha danada, correndo de lá prá cá". A aluna respondeu que uma batalha danada é o mesmo que uma vida agitada, trabalhosa. Empregou o termo numa outra construção, ao afirmar que o colega era "danado mesmo", ou seja, interessado, inteligente. Segundo a SCC (FERRAREZI JR., 2012), considerando os interlocutores, teríamos um sentido maior, especializado, conseguido pela inserção do contexto, pelo cenário de sala de aula. Porém, se isolássemos a fala da aluna 25, "danado" poderia assumir um outro sentido, a depender do contexto; poderia ser uma criança levada, arteira, traquina, ou ainda alguém condenado ao inferno, pode se referir a valentia ("O homem Nordestino é mesmo um danado"), entre outras colocações.

É possível ainda trilhamos pela perspectiva da semântica cultural, observando expressões recorrentes no cordel e aqueles utilizados no cotidiano do alunado. Por exemplo, as expressões "cabra da peste" e "cabra besta", em relação às orações:

\section{I): "O valente sertanejo era mesmo um cabra da peste"}


II): "A peste daquele homem, ninguém queria por perto";

III): "A besta de meu pai pariu";

IV): "A cabra de minha mãe deu à luz";

V): "O jovem se mostrava ser um cabra besta";

Percebemos aqui a riqueza idiomática proveniente do emaranhado cultural que no Nordeste produz expressões e sentidos, podendo ou não ser compreendidos pelos interlocutores de outras regiões brasileiras. Em I, a expressão Cabra (ou caba) da peste refere-se a um sujeito dotado de valentia, corajoso, ousado, resoluto, arrojado. Quando dissociamos as palavras cabra de peste ou cabra de besta criamos outros sentidos, como em II, III e IV diferente de I e V. Em II, peste tem uma conotação de alguém que seja perverso, uma pessoa ruim. Em III enveredamos pelos sentidos polissêmicos da palavra besta, seria o pai uma besta no sentido de ser ignorante, estúpido, ingênuo, e ter parido, expressão que não pode ser entendida de forma literal, pois não se tem a referência de "parir" para o sexo masculino. Ou seja, teria o pai parido alguma ideia, desempenhado alguma função, ou seria mesmo uma besta, a fêmea do cavalo. A mesma análise pode ser efetuada em IV. Em V cabra besta é alguém que se deixar ser enganada, ignorante, "burra", como alguns nordestinos a denominam.

Os sentidos e as expressões, porém, não são dissecados numa demonstração isolada do texto, isto é, do contexto e também do cenário. Os alunos precisam verificar o sentido dessas palavras e o vínculo que elas têm com o ambiente cultural em que foi criado. Por essa razão, em nossos estudos, buscamos apresentar propostas de abordagem didático-pedagógicas atreladas a gêneros textuais diversos, como o cordel, para o desenvolvimento de um trabalho com a leitura na educação básica.

\section{CONSIDERAÇÕES SOBRE O DITO}

O objetivo desse artigo foi promover uma reflexão acerca do ensino de Língua Materna como ênfase na capacidade crítica/reflexiva do alunado, com vistas a atender as demandas educacionais da sociedade contemporânea a partir dos estudos da Semântica de Contextos e Cenários (SCC). Com isso, esperamos fomentar/fortalecer trabalhos que evidenciem as práticas culturais relacionadas aos estudos dos fenômenos linguísticos em âmbitos locais.

Como buscamos demonstrar, é possível promover atividades que envolvam a multiplicidade de usos efetivos da língua(gem) e da leitura nos mais diversos contextos sociais, levando em consideração a interação como lugar constitutivo de formação de sujeitos. Assim o professor de Língua Materna desenvolverá práticas condizentes com as que apontam os Parâmetros Curriculares Nacionais: "buscar desenvolver no aluno seu potencial crítico, sua percepção das múltiplas possibilidades de expressão linguísticas, sua capacitação como leitor efetivo dos mais diversos textos representativos de nossa cultura" (BRASIL, 2002, p.55).

Observamos que a construção cultural dos nordestinos é imensa e muito diversificada, com diferenças regionais bem marcadas. Ao destacar os aspectos semânticos e culturais como abordagem de ensino de língua(gem), esperamos valorizar a transposição dos estudos linguísticos, abrindo espaço para pesquisas multidisciplinares na escola. Ao levar essas ideias transpostas didaticamente para sala de aula, o professor pode abordar a produção de significados no contexto da língua, falando para o aluno sobre a relevância do contexto para interpretação dos variados sentidos. A forma de ver o mundo na perspectiva do estudante, sua visão de referência, seu sistema linguístico associado aos sentidos da cultura... Tudo funcionando como sistema de representação de mundos, a partir de visões de mundo e da associação de palavras e sentidos que formam as representações culturais materializadas em textos que expressão o cotidiano e o imaginário dos falares das cidades.

Diante dos dados apresentados, o professor de Língua Materna não pode desprezar a função de registro cultural das palavras presentes nos textos e nas situações de interação que 
circulam na comunidade escolar, com vistas a desenvolver atividades reflexivas sobre os fenômenos linguísticos, sentidos de palavras e expressões, processos de nomeações metafóricas, para que a própria identidade cultural dos falantes da região seja valorizada. Esse sentimento de identidade ou pertencimento do grupo, de sentir-se representado pela cultura, é preponderante para o ambiente de sala de aula.

\section{REFERENCIAS}

ASSARÉ, Patativa. Emigrações e suas consequências. s/l. s/d.

Cante lá que eu canto cá: filosofia de um trovador nordestino. Editora Vozes, 2008.

BRASIL. Ministério da Educação. Ministério da Educação. Secretaria de Educação Fundamental. Parâmetros Curriculares Nacionais: Pluralidade Cultural. Brasília: MEC, 1998.

PC+ Ensino Médio: orientações educacionais complementares aos PCN na área de Linguagens, códigos e suas tecnologias. Brasília: Ministério da Educação, Secretaria da Educação Média e Tecnológica, 2002.

Diretrizes Curriculares Nacionais da Educação Básica. Brasília, MEC, 2013.

CANDAU, V. M. Ferrão. Ser professor/a hoje: novos confrontos entre saberes, culturas e práticas. Educação (Porto Alegre, impresso), v.37, n.1, p. 33-41, jan/abr, 2014.

FERRAREZI JR. C. Metáfora e função de registro: a visão de Mundo do falante e sua interferência nas Línguas naturais. Linha d'Água, n. 25 (1), p. 67-86, 2012.

Semântica para educação básica. São Paulo: Parábola, 2008.

GERALDI, J. W. Portos de passagens. São Paulo: Martins Fontes, 1991.

O texto na sala de aula. São Paulo: Anglo, 2014.

MELLO, Beliza de Arruda. "Movência" de paradigmas no cordel: do canto ao ciberespaço. In: JÚNIOR, L. A. S. OLIVEIRA, A. P. (Orgs). Literatura e ensino: reflexões e propostas. Natal, RN: EDUFRN, 2013, p. 285-300.

MOREIRA, Antônio Flavio B.; CANDAU, Vera Maria. Indagações sobre currículo: currículo, conhecimento e cultura. Brasília: MEC, Secretaria de Educação Básica, 2007.

RODRIGUES, Linduarte Pereira. Cultura clássica, cultura vulgar: considerações acerca do ideal de autor, leitor e leitura. Sociopoética, Campina Grande, PB, n. , p. 1-16, 2009.

O "entre-lugar" dos folhetos de cordel no século XXI. Boitatá - Revista do GT de Literatura Oral e Popular da ANPOLL - Londrina, PR, 2014. p. 158-176.

Folhetos de cordel no ensino de língua materna: aspectos culturais e formação docente.

Revista do Gelne, Natal, RN, p. 140-167, 2016.

SACRISTÁN, J. Gimeno. Educar e conviver na cultura global: as exigências da cidadania Porto Alegre: Artmed, 2002. 
SILVA, R. N. da. Representação do homem do Nordeste e identidade masculina na literatura de cordel. (Monografia de graduação) - Universidade Estadual da Paraíba - UEPB, Campina Grande, 2014.

SILVA, R. N. da. Folhetos de cordel no letramento escolar: a aula de leitura revisitada. Dissertação (Mestrado) - Universidade Estadual da Paraíba - UEPB, Campina Grande, 2017.

SILVA, Tomaz Tadeu da. O currículo como fetiche: a poética e a política do texto curricular. Belo Horizonte, MG: Autêntica, 2010.

SODRÉ, Muniz. Reinventando a educação: Diversidade, descolonização e redes. Petrópolis, RJ: Vozes, 2012.

Submetido em 30/01/2020

Aceito em 22/05/2020 